\title{
Prevalence of deep caries in preschoolers who underwent either scheduled or emergency dental general anesthesia. Does toothache make a difference? A retrospective analysis
}

Dagmar Schnab1 ${ }^{1 *}$, Felix Fleischer ${ }^{1}$,Annachiara Guarda ${ }^{1}$, Maria Guarda $^{1}$, Lia Marie von Spreckelsen ${ }^{1}$, Marina Riedmann ${ }^{2}$, Johannes Laimer $^{3}$, René Steiner ${ }^{1}$, Robert Gassner ${ }^{3}$ and Herbert Dumfahrt ${ }^{1}$

${ }^{1}$ University Hospital of Dental Prosthetics and Restorative Dentistry, Medical University of Innsbruck, Innsbruck, 6020, Austria

${ }^{2}$ Department of Medical Statistics, Informatics and Health Economics, Medical University of Innsbruck, Innsbruck, 6020, Austria

${ }^{3}$ University Hospital of Cranio-Maxillofacial and Oral Surgery, Medical University of Innsbruck, Innsbruck, 6020, Austria

\begin{abstract}
Background: In children who are unamenable to dental treatment under local anesthesia, dental general anesthesia (DGA) presents a feasible treatment option. In the presence of odontogenic pain/abscess formation, emergency DGA provides immediate treatment (extraction of the causative tooth/teeth). Scheduled DGA in non-pain patients, in contrast, includes the conservation/restoration of teeth displaying early stages of caries. The aim of this retrospective study was the comparative assessment of prevalence of deep caries in preschool children who underwent either scheduled or acute DGA.

Methods: The study sample was composed of 906 children under six years who underwent acute DGA for odontogenic pain and 754 non-pain children under six years diagnosed with carious lesions who underwent scheduled DGA, from January 2008 to June 2014. In both groups, all deeply carious primary teeth were extracted under DGA. Multivariate linear regression analysis was used to assess the effects of age, gender, language affiliation (German-speaking $(G)$ or non-German-speaking $(\mathrm{NG})$ ), and odontogenic pain upon the number of primary teeth extracted under DGA.

Results: The difference in extracted primary teeth between the non-pain and the pain group was statistically highly significant $(4.50 \pm 3.19$ versus $6.50 \pm 4.20)$. Number of tooth extractions was predicted to be almost twice higher in toothache patients than in non-pain patients and 1.21 times higher in NG children than in G children.

Conclusions: Both groups of the study sample presented multiple deep caries. The presence of toothache was associated with higher numbers of tooth extractions. In order to impede childhood caries and its sequels, oral health literacy needs to be increased in (marginalized) population groups at high caries risk. In case of infeasibility of routine dental treatment, children displaying carious lesions should be referred to DGA early in order to prevent the progress of caries and the occurrence of odontogenic pain.
\end{abstract}

\section{Introduction}

Dental caries and its sequels may severely impact children's (oral) health [1-6]. In the light of the caries decline in industrialized Western countries, it might reasonably be expected that the parents' wish for maintenance of their children's oral health should present the incentive to consult a dentist rather than the presence of caries or odontogenic pain [7-11].

The Federal State of Tirol, Austria, has been presenting a high level of education and commitment in general and oral health issues [12,13]. However, a polarization of caries in children of high-risk groups (frequently coming from families presenting a low educational level or a migratory background) has occurred [14]. A lack of oral health literacy and language barriers may be causative. Caries and/or pain constituted the reasons for seeking dental attendance in the preschoolers admitted to dental general anesthesia (DGA) who were investigated in this study [15,16]. DGA presents an accepted treatment method in individuals who are (due to infantile incomprehension, dental anxiety, intellectual and/or physical disablement, or systemic diseases) unamenable to routine dental treatment, even though it requires high expenditure and implicates the risk of anesthetic complications [17-19]. DGA has been shown to enhance children's oral health-related quality of life and dental behavior [20-24]. In acute settings, DGA provides a rapid onset of action and an optimal titration of anesthetics [25]. However, emergency DGA presents an organizational challenge with respect to the $24 / 7$ provision of pre-, peri- and postoperative care requiring the respective medical and nursing staff. For the children's benefit, scheduled DGA in non-pain patients displaying carious lesions seems preferable to a stressful emergency procedure, also with respect to the possible conservation/restoration of carious teeth instead of tooth extractions. The question of interest in this study was, if the presence of toothache is associated with higher numbers of deeply carious primary teeth. The null hypothesis was that the prevalence of deep caries is equal

*Correspondence to: Dagmar Schnabl, University Hospital of Dental Prosthetics and Restorative Dentistry, Medical University of Innsbruck, Innsbruck, 6020, Austria, Tel: +43 512504 27162; Fax +43 512504 27157; E-mail: dagmar. schnabl@tirol-kliniken.at

Key words: childhood caries, deep caries, dental anxiety, dental general anesthesia, dental neglect, odontogenic pain

Received: June 24, 2019; Accepted: July 05, 2019; Published: July 09, 2019 
Schnabl D (2019) Prevalence of deep caries in preschoolers who underwent either scheduled or emergency dental general anesthesia. Does toothache make a difference? A retrospective analysis

in non-pain preschool children treated under scheduled DGA and in preschool children who had unscheduled DGA for odontogenic pain.

\section{Methods}

\section{Subjects}

From January $1^{\text {st }} 2008$ to June $30^{\text {th }} 2014$, 906 consecutive patients younger than six years presenting with odontogenic pain and/or swelling received unscheduled emergency DGA at the University Hospital of Cranio-Maxillofacial and Oral Surgery of Innsbruck. In the same period, 754 consecutive cases of non-pain children younger than six years diagnosed with carious lesions received scheduled DGA at University Hospital of Dental Prosthetics and Restorative Dentistry of Innsbruck. All children of this convenience sample $(n=1660)$ investigated in this retrospective study were unamenable to treatment under local anesthesia and were thus treated under DGA. At registration, non-pain children (not suffering acute or enduring pain, diagnosed with carious lesions and referred by dentists in private practices) were placed on a waiting list for scheduled DGA. Children of the pain group (presenting on their own accord or upon a dentist's referral), in contrast, were in need for immediate treatment. In children suffering pain and frequently presenting abscess formation, DGA was performed either at the day of admission, or (along with antiphlogistic and/or antibiotic treatment) at the following day (in order to ensure an empty stomach or for reasons of capacity). In both groups of children, after a preoperative clinical and radiological assessment (as far as possible), all deeply carious primary teeth presenting vital or avital pulp exposition (on excavation) were extracted under DGA. In the course of emergency DGA, teeth presenting early stages of decay and requiring restorative therapy remained untreated. For these teeth, further (restorative) treatment in a scheduled setting had to be arranged. During scheduled DGA, in contrast, restorative treatment of carious teeth was accomplished, while deeply carious teeth were extracted. According to internal directives, neither pulpotomy nor endodontic treatment were performed under DGA, in order to keep duration of general anesthesia short and to ensure postoperative absence of pain. Dental treatment under DGA was carried out by changing consultants on duty.

\section{Study design and data acquisition}

The study was set up as a retrospective analysis of anonymized data extracted from digital patient files. Ethical approval by the ethics committee of the Medical University of Innsbruck was obtained in advance (study IDs AN2014-0269 341/4.8 (3621a) and AN2015-0063 347/4.9).

The following anonymized data were extracted from case files, coded by numbers, and listed in a table (Microsoft Excel, MS office 2016, Microsoft, Redmond, WA, USA):

a) Date of birth

b) Date of DGA

c) Date of admission in non-pain children

d) Gender: male/female

e) Language affiliation: German-speaking (G)/non-German-speaking (NG)

f) Preoperative orthopantomogram (OPG) available: yes/no

g) Number of primary teeth extracted under DGA
Date of DGA and date of admission were used to calculate the waiting time in non-pain children assigned to scheduled DGA. "NG" was assigned to children whose both parents' or single parent's first language was declaredly not German. The language question was answered by the parents at registration. (A similar cultural background and conception of oral health compared to Tirolean standards was presumed in $\mathrm{G}$ immigrant children from the neighboring countries Germany, Switzerland and South Tirol, Italy).

\section{Data analysis}

Basic descriptive analysis of patients' data was performed. Numerical data were generally reported as mean \pm standard deviation and categorical data were summarized as absolute and relative frequencies. For the analysis of associations between categorical data, Chi-square test was used. For the comparative analysis of not normally distributed data in subgroups, Mann-Whitney $U$ test was used. Shapiro-Wilk test was used to test the normality of data distribution. Multivariate linear regression analysis was used to assess the effects of age, gender, language affiliation, and the presence of pain upon the number of primary teeth extracted under DGA. Significance level was set at $\mathrm{p}=0.05$. All computations were performed in SPSS software (SPSS Statistics Version 21, IBM, Armonk, NY, USA).

\section{Results}

\section{Subjects}

In the non-pain group $(\mathrm{n}=906)$ mean age at the date of admission to the waiting list was $3.98 \pm 1.01$ years. The mean waiting time from the date of registration to the date of DGA was $4.50 \pm 3.19$ months. Mean age at the date of DGA was $4.28 \pm 1.01$ years. In the pain group (n $=754$ ) mean age at the date of DGA was $4 \pm 1.56$ years. The difference in age at the date of admission ( $3.98 \pm 1.01$ versus $4 \pm 1.56)$ between the two groups was not statistically significant ( $\mathrm{p}=0.562$; Mann-Whitney $\mathrm{U}$ test).

The distribution of gender, language affiliation, and the availability of a preoperative OPG in non-pain and toothache children is depicted in Table 1 . The difference in language affiliation was statistically significant ( $p=0.02$; Chi-Square test) and the availability of a preoperative OPG was statistically highly significant $(\mathrm{p}<0.001$; Chi-Square test).

\section{Extracted primary teeth}

The mean number of extracted primary teeth was $4.50 \pm 3.19$ per non-pain patient and $6.50 \pm 4.20$ per patient receiving acute DGA for odontogenic pain. The difference in extracted primary teeth was statistically highly significant ( $\mathrm{p}<0.001$; Mann-Whitney U test).

\section{Multivariate regression analysis}

In the multivariate regression model designed to assess the effects of age, gender, language affiliation, and the presence of pain upon the number of primary teeth extracted under DGA, regression coefficients for the presence of pain and for language affiliation were statistically significant (Table 2). Number of extractions of deeply carious primary teeth was predicted to be almost twice higher in toothache patients as compared to non-pain patients (odds: $1.95,95 \%$ confidence interval (CI):1.60 to 2.31) and 1.21 times higher in NG children as compared to G children (odds: $1.21,95 \%$ CI: 0.86 to 1.57 ).

\section{Discussion}

The null hypothesis of an equal prevalence of deep caries in preschoolers presenting for DGA without and with toothache was 
Schnabl D (2019) Prevalence of deep caries in preschoolers who underwent either scheduled or emergency dental general anesthesia. Does toothache make a difference? A retrospective analysis

Table 1. Sample characteristics

\begin{tabular}{|l|c|c|c|}
\hline \multirow{2}{*}{ Gender } & Male & Non-pain n= 906 & Pain n= 754 \\
\cline { 2 - 4 } & Female & $309(56.2 \%)^{\mathrm{a}}$ & $427(56.6 \%)^{\mathrm{a}}$ \\
\hline \multirow{2}{*}{ Language affiliation } & $\mathrm{G}$ & $501(53.8 \%)^{\mathrm{a}}$ & $327(43.4 \%)^{\mathrm{a}}$ \\
\cline { 2 - 4 } & NG & $405(44.7 \%)^{\mathrm{b}}$ & $373(49.5 \%)^{\mathrm{b}}$ \\
\hline \multirow{2}{*}{ Orthopantomogram } & Yes & $539(59.5 \%)^{\mathrm{c}}$ & $381(50.5 \%)^{\mathrm{b}}$ \\
\cline { 2 - 4 } & No & $367(40.5 \%)^{\mathrm{c}}$ & $105(13.9 \%)^{\mathrm{c}}$ \\
\hline
\end{tabular}

n, number; G, German-speaking; NG non-German-speaking

a, $\mathrm{p}=0.88 ;{ }^{\mathrm{b}}, \mathrm{p}=0.02 ;{ }^{\mathrm{c}}, \mathrm{p}<0.01$; Chi-Square test

Table 2. Multivariate linear regression analysis for the assessment of the effects of age, gender, language affiliation, and the presence of pain upon the number of primary teeth extracted under dental general anesthesia.

\begin{tabular}{|l|c|c|c|}
\hline & $\begin{array}{c}\text { Odds } \\
\text { ratio }\end{array}$ & $\begin{array}{c}\text { 95\% Confidence } \\
\text { Interval (lower limit) }\end{array}$ & $\begin{array}{c}\text { 95\% Confidence } \\
\text { Interval (upper limit) }\end{array}$ \\
\hline Age $^{\mathrm{a}}$ & 0.045 & -0.117 & 0.208 \\
\hline Gender $^{\mathrm{b}}$ & 0.194 & -0.159 & 0.547 \\
\hline Language affiliation $^{\mathrm{c}}$ & 1.213 & 0.861 & 1.565 \\
\hline Pain $^{\mathrm{c}}$ & 1.951 & 1.596 & 2.307 \\
\hline
\end{tabular}

a, $\mathrm{p}=0.585 ;{ }^{\mathrm{b}}, \mathrm{p}=0.281 ;{ }^{\mathrm{c}}, \mathrm{p}<0.001$

rejected. Each of the two groups of preschool children presented a selection of individuals at high caries risk. While in $59.5 \%$ of the children of the non-pain group, cooperation sufficed to take a preoperative OPG, only $13.9 \%$ of the pain group patients were convertible to have an OPG taken. Dental anxiety is a common problem in children worldwide and its prevalence is inversely associated with age [26-28]. Acute odontogenic pain seems to increase dental anxiety and to reduce cooperation, rendering even orthopantomography impossible.

NG children were mainly of Turkish and Eastern European provenance, as these two ethnic groups present the majority of NG speaking immigrants in Tirol and its neighboring state, Vorarlberg $[29,30]$. The percentage of NG children being higher in the pain than that in the non-pain group (50.5\% versus $44.5 \%$ ) indicates that the NG group tends to seek dental treatment rather because of the presence of pain than for preventive or restorative reasons. Furthermore, assignment to the NG group increased odds for extractions of primary teeth 1.2 fold. The presence of odontogenic pain almost doubled odds for extractions. Remarkably, also children of the non-pain group presented a mean of $4.50 \pm 3.19$ profoundly carious teeth that were extracted. This may partly be due to caries progression during the waiting period of $4.50 \pm 3.19$ months from registration to DGA.

In the course of the recent decades, extensive preventive measures (such as imparting of knowledge of appropriate oral care and a toothfriendly diet, the topic or systemic use of fluorides, and fissure sealing) were implemented in Austria [12-14]. Thus, neither the presence of carious decay nor odontogenic pain, but prophylaxis should present the major reason triggering the first and further dental visits of children. Anywhere in Tirol, access to dental care providers is available within a reasonable distance. The costs for dental treatment by panel doctors (as well as the costs for DGA in a public hospital) are covered by the statutory public health insurance system.

Parents' failure in providing oral care to their children, in seeking, or in complying with dental treatment has been associated with child neglect and abuse [31-33]. However, in most cases, a lack of parents' oral health literacy seems to be the cause of childhood caries. Health care programs should therefore focus on the adjustment of oral health levels in high risk groups (including ethnical minorities) in order to avoid carious decay and, most importantly, odontogenic pain. Preventive approaches should thereby address parents-to-be and parents of infants and include education in nutrition, lifestyle and domestic oral hygiene $[9,27,34]$. Maternal oral health is associated with dental health of their children [35]. A routine dental examination of expectant mothers in the course of antenatal care, where necessary followed by a dental consultation, might thereby serve as a first step towards a harmonization of oral health levels in different population groups. Moreover, parents should be enjoined to adhere to regular dental attendance for their children, beginning with the eruption of the first teeth.

Limitations of this study are owed to its retrospective character. Information on the parents' socioeconomic situation, educational level, or the country of provenance was not available. The reasons for non-amenability to treatment under local anesthesia (infantile incomprehension/anxiety, disability, or systemic disease) had not consistently been documented.

In summary, $\mathrm{G}$ and NG children treated under scheduled or unscheduled DGA presented multiple deep caries. The presence of toothache was associated with higher numbers of extracted primary teeth. As a consequence, in population groups at high caries risk, the parents' awareness of the responsibility for their children's health and well-being should be raised in consideration of the sequels of (untreated) caries. Pediatricians are strongly encouraged to refer children to regular dental consultations. Dental attendance should start as soon as baby teeth are erupting. In case of unsuccessful treatment attempts of carious lesions under office conditions, children should be referred to a center that offers DGA (or alternative treatment approaches such as behavior management, hypnodontia, or conscious sedation) in order to prevent the progress of caries and, most importantly, the occurrence of odontogenic pain.

\section{Autorship and contributorship}

DS, JL, RS, HD and RG conceived and designed the study. FF, AG, MG and LMS collected the data. MR performed the statistical analysis. DS wrote the manuscript. All authors proofread and approved the manuscript.

\section{Acknowledgements}

Thanks to Viktoria Dudasne and Barbara Prantner for their assistance in organizational concerns and the draw up of tables and to Julia Kirchebner for the provision of writing services.

\section{Funding information}

The study was supported by the Medical University of Innsbruck, Austria. No funding was obtained.

\section{Competing interests}

The authors declare that there are no competing interests in this study.

\section{Ethics approval}

The present study was carried out in accordance with the Declaration of Helsinki and ethical approval was obtained by the ethical committee of the Medical University of Innsbruck (study IDs AN2014-0269 341/4.8 (3621a) and AN2015-0063 347/4.9). 
Schnabl D (2019) Prevalence of deep caries in preschoolers who underwent either scheduled or emergency dental general anesthesia. Does toothache make a difference? A retrospective analysis

\section{References}

1. National Institute of Dental and Craniofacial Research (2000) What is oral health? In: Oral health in America: A report of the Surgeon General. Rockville: US Department of Health and Human Services, National Institute of Dental and Craniofacial Research.

2. Rane JV, Winnier J, Bhatia R (2017) Comparative assessment of oral health related quality of life of children before and after full mouth rehabilitation under general anaesthesia and local anaesthesia. J Clin Diagn Res 11: ZC23- ZC26. [Crosssref]

3. Goodwin M, Sanders C, Davies G, Walsh T, Pretty IA (2015) Issues arising following a referral and subsequent wait for extraction under general anaesthetic: impact on children. BMC Oral Health 15: 3. [Crossref]

4. Leal SC, Bronkhorst EM, Fan M, Frencken JE (2012) Untreated cavitated dentine lesions: impact on children's quality of life. Caries Res 46: 102-106. [Crossref]

5. Han X, An J, Zhang Y, Gong X, He Y (2015) Risk factors for life-threatening complications of maxillofacial space infection. J Craniofac Surg 27: 385-390. [Crossref]

6. Bali RK, Sharma P, Gaba S, Kaur A, Ghanghas P (2015) A review of complications of odontogenic infections. Natl J Maxillofac Surg 6: 136-143. [Crossref]

7. Petersen PE (2005) The burden of oral disease: challenges to improving oral health in the 21st century. Bull World Health Organ 83: p. 3. [Crossref]

8. Petersson GH, Bratthall D (1996) The caries decline: a review of reviews. Eur J Oral Sci 104: 436-443. [Crossref]

9. Wagner Y, Heinrich-Weltzien R (2017) Risk factors for dental problems: Recommendations for oral health in infancy. Early Hum Dev 114: 16-21. [Crossref]

10. Mileva SP, Kondeva VK (2010) Age at and reasons for the first dental visit. Folia Med (Plovdiv) 52: 56-61. [Crossref]

11. Cunha RF, Matos JX, Marfinati SM (2004) Dentistry for babies: why do parents seek dental care? J Clin Pediatr Dent 28: 193-194. [Crossref]

12. Bodenwinkler A, Kerschbaum J, Sax G (2012) Zahnstatus 2011 Sechsjährige in Österreich. Vienna: Gesundheit Österreich GmbH.

13. Gesundheit Österreich GmbH (2012) Zahngesundheit. In: Tiroler Gesundheitsbericht Innsbruck: Amt der Tiroler Landesregierung.

14. Luckner-Hornischer A, Halder-Kessler M, Erber-Kuprian A, Holzhammer G (2009) Zahnstatusbericht Sechsjährige mit und ohne Migrationshintergrund Tirol 2006. Innsbruck: Amt der TirolerLandesregierung.

15. Kanupuru KK, Fareed N, Sudhir KM (2015) Relationship between oral health literacy and oral health status among college students. Oral Health Prev Dent 13: 323-330. [Crossref]

16. Blizniuk A, Ueno M, Zaitsu T, Kawaguchi Y (2015) Association of oral health literacy with oral health behaviour and oral health status in Belarus. Community Dent Health 32: 148-152. [Crossref]

17. American Dental Association (2016) Guidelines for the Use of Sedation and General Anesthesia by Dentists Adopted by the ADA House of Delegates. Chicago: American Dental Association.

18. Rashewsky S, Parameswaran A, Sloane C, Ferguson F, Epstein R (2012) Time and cos analysis: Pediatric dental rehabilitation with general anesthesia in the office and the hospital settings. Anesth Prog 59: 147-153. [Crossref]
19. De Francisci G, Papasidero AE, Spinazzola G, Galante D, Caruselli M, et al. (2013) Update on complications in pediatric anesthesia. Pediatr Rep 5: e2. [Crossref]

20. Eidelmann E, Faibis S, Peretz B (2000) A comparison of restorations for children with early childhood caries treated under general anesthesia or conscious sedation. Pediatr Dent 22: 33-37. [Crossref]

21. Karim ZA, Musa N, Noor SN (2008) Utilization of dental general anaesthesia for children. Malays J Med Sci 15: 31-39. [Crossref]

22. Blumer S, Costa L, Peretz B (2017) Success of dental treatments under behavior management, sedation and general anesthesia. J Clin Pediatr Dent 41: 308-311. [Crossref]

23. Song JS, Hyun HK, Shin TJ, Kim YJ (2018) Effects of dental treatment and systemic disease on oral health-related quality of life in Korean pediatric patients. BMC Oral Health 18: 92. [Crossref]

24. Malamed SF (2018) General anesthesia. In: Malamed S.F. Sedation. A guide to patient management. St. Louis: Elsevier pp. 405-433.

25. Guney SE, Araz C, Tirali RE, Cehreli SB (2018) Dental anxiety and oral health-related quality of life in children following dental rehabilitation under general anesthesia or intravenous sedation: A prospective cross-sectional study. Niger J Clin Pract 21: 1304 1310. [Crossref]

26. Cianetti S, Lombardo G, Lupatelli E, Pagano S, Abraha I, et al. (2017) Dental fear/ anxiety among children and adolescents. A systematic review. Eur J Paediatr Dent 18: 121-130. [Crossref]

27. Raja GH, Malik FS, Bashir U, Attaullah (2015) Dental anxiety among children of age between 5 to 10 years visting a teaching dental hospital in Islamabad, Pakistan. $J$ Ayub Med Coll Abbottabad 27: 587-590. [Crossref]

28. Maistorovic M, Morse DE, Do D, Lim LI, Herman NG, et al. (2014) Indicators of dental anxiety in children just prior to treatment. $J$ Clin Pediatr Dent 39: 12-17. [Crossref]

29. Dobler C, Kaiser M (2015) Demographische Daten Tirol 2014. Innsbruck: Amt der Tiroler Landesregierung, Sachgebiet Landesstatistik und tiris.

30. Wagner Y, Greiner S, Heinrich-Weltzien R (2014) Evaluation of an oral health promotion program at the time of birth on dental caries in 5-year-old children in Vorarlberg, Austria. Community Dent Oral Epidemiol 42: 160-169. [Crossref]

31. Costacurta M, Benavoli D, Arcudi G, Docimo R (2016) Oral and dental signs of child abuse and neglect. Oral Implantol (Rome) 8: 68-73. [Crossref]

32. Kvist T, Annerbäck EM, Dahllöf G (2017) Oral health in children investigated by social services on suspicion of child abuse and neglect. Child Abuse Negl 76: 515-523. [Crossref]

33. Sillevis Smitt H, de Leeuw J, de Vries T (2017) Association Between Severe Denta Caries and Child Abuse and Neglect. J Oral Maxillofac Surg 75: 2304-23066. [Crossref]

34. Wagner Y, Heinrich-Weltzien R (2017) Evaluation of a regional German interdisciplinary oral health programme for children from birth to 5 years of age. Clin Oral Investig 21: 225-235. [Crossref]

35. Olak J, Nguyen MS, Nguyen TT, Nguyen BBT, Saag M (2018) The influence of mothers' oral health behaviour and perception thereof on the dental health of their children. EPMA J 9: 187-193. [Crossref]

Copyright: (C2019 Schnabl D. This is an open-access article distributed under the terms of the Creative Commons Attribution License, which permits unrestricted use, distribution, and reproduction in any medium, provided the original author and source are credited. 